\title{
LA CUSTODIA DEL TERRITORIO COMO INSTRUMENTO COMPLEMENTARIO PARA LA PROTECCIÓN DE ESPACIOS NATURALES
}

\author{
SANTIAGO M. ÁLVAREZ CARREÑO \\ Profesor titular de Derecho Administrativo \\ Universidad de Murcia \\ santialv@um.es
}

\begin{abstract}
SONIA M. HERNÁNDEZ LÓPEZ
Técnico facultativo superior de Organismos Autónomos del Ministerio de Medio Ambiente Confederación Hidrográfica del Segura

maria.hernandez@chsegura.es
\end{abstract}

Recibido: 11 de abril de 2011 / Aceptado: 20 de mayo de 2011

RESUMEN: La presente nota analiza la evolución normativa de la custodia del territorio como estrategia complementaria de protección de los espacios naturales caracterizada por las notas de participación y voluntariedad y que goza de una creciente vitalidad y posibilidades de futuro. En especial, se trata de subrayar la evolución de los mecanismos de protección que, si bien descansaban en el ejercicio unilateral de potestades administrativas, de modo creciente se orientan a estrategias acordadas con los sectores interesados y afectados, como modo de conseguir mayor apoyo social y colaboración de los particulares en la consecución de los fines de interés general, en este caso, la utilización racional de los recursos naturales, la garantía del derecho a disfrutar de un medio ambiente adecuado y el más cabal cumplimiento de los deberes de protección. 
RESUM: La nota present analitza l'evolució normativa de la custòdia del territori com a estratègia complementària de protecció dels espais naturals caracteritzada per les notes de participació i voluntarietat i que gaudeix d'una vitalitat creixent i possibilitats de futur. En especial, es tracta de subratllar l'evolució dels mecanismes de protecció que, si bé descansaven en l'exercici unilateral de potestats administratives, de manera creixent s'orienten a estratègies acordades amb els sectors interessats i afectats, com a manera d'aconseguir major suport social i col-laboració dels particulars en la consecució de les finalitats d'interès general, en aquest cas, la utilització racional dels recursos naturals, la garantia del dret a gaudir d'un medi ambient adequat i el compliment més adequat dels deures de protecció.

\begin{abstract}
This note analyzes the legal evolution of the guard of territory as a complementary strategy of protection of natural areas, which is characterized by the notes of participation and voluntary nature, and which enjoys a growing vitality and future expectations. Specially, it is intended to underline the evolution of the protection ways, which in the past relied in the unilateral exercise of administrative authority and now are increasingly oriented to shared strategies with the stakeholders, as a way to get more social support and collaboration of citizens in achieving collective aims, in this case, the rational use of natural resources, the right to enjoy an adequate environment and the adequate fulfilment of the protection duties.
\end{abstract}

PALABRAS CLAVE: espacios naturales — estrategias de protección — participación entidades de custodia del territorio.

PARAULES CLAU: espais naturals — estratègies de protecció — participació — entitats de custòdia del territori.

KEYWORDS: natural areas - protection estrategies — participation — entities of guardo $\mathrm{f}$ the territory. 
Sumario: I. Introducción. II. Evolución histórica en España de la custodia del territorio. III. La custodia del territorio en el marco de los instrumentos de protección ambiental al servicio de la Administración pública. IV. El régimen jurídico de la custodia del territorio diseñado por la Ley 42/2007, de 13 de diciembre, del Patrimonio Natural y de la Biodiversidad. V. Conclusiones. VI. Bibliografía.

\section{INTRODUCCIÓN}

El ordenamiento jurídico español pone a disposición de los poderes públicos diversas herramientas que les permiten cumplir el mandato constitucional de velar por el uso racional de los recursos naturales. Sin embargo, en la actualidad lograr los objetivos de conservación del entorno exige ir más allá de los instrumentos tradicionales de elaboración normativa, o de declaración de espacios naturales. Las sociedades más avanzadas y activas exigen que se complementen las políticas públicas mediante mecanismos novedosos que permitan involucrar a todos los sectores. Entre estas se debe incluir la custodia del territorio, instrumento aplicable específicamente a los espacios naturales y que se basa en la voluntariedad y participación activa de los propietarios. Esta estrategia complementaria de protección, como lo confirman los recientes estudios de Pallarés (2010: 219-246) y el coordinado por Barreira (2010: 279 pp.), goza de una creciente vitalidad y perspectivas de futuro.

Sin embargo, para conseguir una aplicación eficiente de esta y obtener beneficios en favor del interés público general resulta indispensable que se diseñe un marco jurídico completo que brinde seguridad a los agentes sociales interesados en su puesta en marcha. Esta claridad y fundamento normativo se han conseguido finalmente a través de la Ley 42/2007, de 13 de diciembre, del Patrimonio Natural y de la Biodiversidad. A partir de ese momento, la aplicación real y eficiente de la custodia del territorio requerirá la aceptación social y el apoyo que las diferentes administraciones públicas otorguen a las iniciativas concretas en este ámbito. En efecto, la participación en la conservación de la biodiversidad no puede ya reducirse a la inclusión de representantes de los diversos sectores implicados en órganos colegiados, sino que requiere la iniciativa privada para que colabore de forma voluntaria en la protección de espacios, como un complemento importante a la intervención pública (López Ramón, 2009: 269).

Para ello, resulta fundamental que los agentes sociales y los diferentes organismos públicos reconozcan las posibilidades que les brinda la custodia del territorio en la gestión de los recursos naturales, y asuman la difícil tarea de conocer y dominar sus herramientas y apuesten 
por su aplicación como medida viable que apoye el cumplimiento de los objetivos ambientales.

El análisis que se desarrolla a continuación permitirá enmarcar la custodia del territorio en su evolución histórica y en el marco de los instrumentos jurídicos con los que cuenta la Administración pública para velar por el interés general, para analizar seguidamente su regulación inicial prevista en la Ley 42/2007. Aportaciones todas ellas indispensables si se quiere responder a la creciente demanda de la sociedad civil de disponer de medidas de participación más activa en la toma de decisiones y de instrumentos de gestión del medio ambiente.

\section{EVOLUCIÓN HISTÓRICA EN ESPAÑA DE LA CUSTODIA DEL TERRITORIO}

Los primeros ejemplos de custodia del territorio enfocados a la protección de espacios naturales aparecen en los Estados Unidos a finales del siglo XIX con la creación de The Trustees of Public Reservations; en Reino Unido, esta figura del land stewardship toma cuerpo con el surgimiento del National Trust.

En España, la custodia del territorio comenzó a aplicarse sin contar con una seguridad jurídica propia; sin embargo, las primeras experiencias se mostraron tímidas pero eficaces en sus objetivos. Se considera a Félix Rodríguez de la Fuente como el iniciador de la custodia del territorio en nuestro país al promover, junto con WWF/Adena, la creación del Refugio de Rapaces de Montejo de la Vega (Segovia) en 1975. Se deben recordar asimismo las primeras iniciativas impulsadas desde ADENEX - Asociación para la Defensa de la Naturaleza y los Recursos de Extremadura - en la misma época, a través del arrendamiento de dos fincas en la zona de Monfragüe amenazadas por cultivos forestales, que contribuyeron a la declaración del primer parque natural de Extremadura en 1979.

En la expansión de la custodia del territorio como filosofía eficaz para la conservación de la naturaleza, el paisaje y el patrimonio cultural en nuestro país, han tenido un papel relevante una serie de convocatorias de divulgación e intercambio de experiencias al respecto. Entre ellas destacan las Jornadas Internacionales de Custodia del Territorio celebradas del 9 al 11 de noviembre del 2000, en las que se elaboró la conocida como Declaración de Montesquiu, que identificó cuatro retos prioritarios que debían permitir la implicación del sector privado en la conservación del territorio: el establecimiento de un marco legislativo y fiscal que promueva las iniciativas voluntarias de custodia, basándose en el principio de menor carga tributaria por 
mayores servicios o beneficios ambientales generados; la expansión de un clima de confianza y cooperación entre las partes implicadas; la educación, formación y participación de las personas involucradas en la custodia del territorio, y, por último, la disponibilidad de recursos económicos y fiscales que consoliden dicha filosofía de conservación.

Muchos de estos retos fueron rápidamente identificados y abordados; sin embargo, no fue hasta la aprobación de la Ley estatal del Patrimonio Natural y de la Biodiversidad, a finales del año 2007, cuando se plantearon soluciones reales a estos retos. No obstante, dicho tratamiento jurídico ha sido calificado como parcial y demandante de un "necesario desarrollo [...] y cuya responsabilidad principal corresponde en este momento a las Comunidades Autónomas y al Estado central" (Propuesta de conclusiones de las III Jornadas Estatales sobre Custodia del Territorio).

La Región de Murcia ha desempeñado un papel importante en la expansión de la custodia del territorio mediante la celebración de las tres Jornadas Estatales sobre Custodia del Territorio en las instalaciones del CEMACAM en Torre Guil bajo la dirección de la Cátedra Unesco de Territorio y Medio Ambiente de la Universidad Rey Juan Carlos y con el patrocinio de la Caja de Ahorros del Mediterráneo (CAM). La primera de dichas Jornadas tuvo lugar en el año 2004 y constató la coherencia de la custodia del territorio como nueva filosofía de gestión, dentro de la Estrategia Nacional de Conservación y Uso Sostenible de la Diversidad Biológica aprobada en 1999. Se puntualizó, asimismo, la necesidad de crear un grupo de trabajo - o cualquier otra fórmula de contacto - que permitiera el diálogo entre entidades, propietarios y poderes públicos con objeto de dar a conocer a la sociedad los beneficios derivados de la custodia del territorio, así como para garantizar la continuidad de sus iniciativas.

Las II Jornadas Estatales organizadas en el año 2006 continuaron con el objetivo de promover la custodia como iniciativa complementaria a los esfuerzos de la Administración en la conservación de la biodiversidad. Buen ejemplo de ello fue el compromiso asumido en el seno de estas jornadas por parte del entonces Ministerio de Medio Ambiente de convocar un foro-reunión en el que se dieran cita las diferentes entidades y organizaciones vinculadas a la custodia del territorio para compartir opiniones y propuestas que delimitaran un marco de actuación coordinado. El Foro-Reunión sobre Custodia del Territorio se celebró en Madrid el 16 de noviembre de 2006, y es considerado como la primera gran convocatoria relativa a la custodia del territorio en la que los poderes públicos se implicaron de manera expresa. 
En las III Jornadas Estatales sobre Custodia del Territorio celebradas del 23 al 25 de mayo de 2008 se adoptaron diversas conclusiones; se considera que las entidades y administraciones públicas deben esforzarse por garantizar la implicación activa de los agentes sociales y económicos en la custodia, para lo cual deberán concretar medidas específicas tales como la formación e información a dichos colectivos, su incorporación a las redes de custodia existentes o el desarrollo de futuros encuentros; se señala la necesidad prioritaria de fortalecer y consolidar la custodia del territorio como movimiento a nivel estatal; se expresa la conveniencia, además, de crear un sello de identidad o acreditación de las iniciativas de custodia que garantice su calidad y eficacia y su valoración por parte de la sociedad; se mantiene la necesidad, como ya se determinó en convocatorias anteriores, de crear por parte del Gobierno de España un régimen de incentivos fiscales para el desarrollo y la promoción de proyectos de custodia del territorio, $\mathrm{y}$, finalmente, se atribuye a los municipios un papel relevante en la aplicación de técnicas de custodia sobre terrenos de titularidad pública, a la vez que se anima a las diferentes administraciones a promover iniciativas de delegación de la gestión de áreas previamente inventariadas a entidades sociales y ciudadanas.

Las IV Jornadas Estatales se celebraron en el norte de España para, tal y como se reconoce en su programa, facilitar la asistencia a entidades de esta zona que hasta el momento no habían estado demasiado representadas en las anteriores jornadas celebradas en la Región de Murcia. Como detalle anecdótico de estas jornadas, cabe destacar que entre sus colaboradores se encuentra la Fundación Félix Rodríguez de la Fuente, cuyo fundador es considerado el pionero en prácticas de custodia del territorio, con lo que así se continúa su legado. Las IV Jornadas Estatales sirvieron fundamentalmente para dar a conocer los avances en la materia después de los primeros apoyos institucionales y normativos alcanzados, para promover nuevas iniciativas y para servir de intercambio de conocimientos y experiencias entre las distintas entidades involucradas, así como para animar a que otras entidades deseosas de introducirse en esta filosofía de conservación den, al fin, el primer paso.

Otros acontecimientos relevantes que constatan la consolidación de este movimiento en nuestro país son la Plataforma Estatal de Custodia del Territorio de la Fundación Biodiversidad, la creación de distintas redes de entidades de custodia o el incremento sustancial y progresivo de la superficie de terreno adherida a iniciativas de custodia.

La Plataforma Estatal es uno de los proyectos más ambiciosos y esperados por los diferentes agentes involucrados en la materia. Su objetivo es el de contribuir al desarrollo de la custodia del territorio en el Estado español mediante la divulgación y el impulso de esta filosofía de 
conservación. Con dicha finalidad la Plataforma ha creado el Foro de Custodia del Territorio, un listado de las redes de custodia del territorio que hasta el momento se han establecido en algunas comunidades autónomas, y el Inventario de Iniciativas de Custodia del Territorio, dentro de las cuales la Región de Murcia ocupa un lugar destacado al ser la segunda comunidad autónoma, después de Cataluña, con mayor número de iniciativas registradas.

Otra entidad de reciente creación que promueve la custodia del territorio es el Foro Estatal de Custodia del Territorio. No hay que confundir este foro, que surge de la sociedad civil y tiene personalidad jurídica propia, con la Plataforma Estatal de Custodia del Territorio, que es más una iniciativa pública, por cuanto nace de la Fundación Biodiversidad (perteneciente al Ministerio de Medio Ambiente y Medio Rural y Marino) como consecuencia de su creciente implicación en estrategias conservacionistas. Aunque los comienzos del Foro Estatal son más que recientes (de hecho, en las IV Jornadas Estatales se firmó el convenio de colaboración entre las entidades que forman parte de su junta preconstitutiva), su necesidad y eficacia (que deberá ir demostrando con el paso del tiempo) quedan avaladas por las entidades que constituyen su junta: Asociación Galega de Custodia del Territorio, Associació Valenciana de Custòdia i Gestió Responsable del Territori (Avinença), Fundación Urdaibai, Impuls a la Custòdia del Territori a les Illes Balears (ICTIB), Ínsulas/Red Andaluza de Custodia del Territorio y la Xarxa de Custòdia del Territori. Por otro lado, la Fundación Félix Rodríguez de la Fuente ha asumido la Secretaría Técnica del Foro.

De este modo, la custodia del territorio ha ido incrementando su presencia en las iniciativas promovidas por entidades sin ánimo de lucro y por las administraciones públicas, alentadas unas y otras por la buena y progresiva acogida de la custodia del territorio en la sociedad. Así, manifestaciones de estos acuerdos de custodia se encontraban ya regulados en los denominados "contratos ambientales para la sostenibilidad de las explotaciones" (CASE) previstos en el Decreto Foral 360/2004, de 22 de noviembre, de declaración del paisaje protegido de los Montes de Valdorba de Navarra, además de otras iniciativas a nivel municipal (Hervás Más, 2009: 364). 


\section{LA CUSTODIA DEL TERRITORIO EN EL MARCO DE LOS INSTRUMENTOS DE PROTECCIÓN AMBIENTAL AL SERVICIO DE LA ADMINISTRACIÓN PÚBLICA}

El artículo 45.2 de la Constitución española determina que "los poderes públicos velarán por la utilización racional de todos los recursos naturales, con el fin de proteger y mejorar la calidad de la vida y defender y restaurar el medio ambiente, apoyándose en la indispensable solidaridad colectiva". Este precepto constitucional ha fundamentado los diferentes instrumentos públicos de protección del medio ambiente. En concreto, la Administración pública — principal receptora del mandato de protección ambiental— puede, como se sabe, utilizar para este fin específico el conjunto de potestades que tiene, de forma general, reconocidas. Así, la Administración pública usará su potestad normativa (reglamentos ambientales), expropiatoria (fin o utilidad pública de carácter ambiental), contractual (contratos administrativos cuyo objeto sean obras, servicios o suministros de carácter ambiental), sancionadora (sanciones ambientales), de fomento (premios ambientales, campañas de concienciación, subvenciones para actividades relevantes en este campo), tributaria (fiscalidad ambiental) y planificadora (de especial importancia, a pesar de carecer todavía de un régimen jurídico básico, en determinados sectores: planificación ecológica de espacios protegidos - PORN-, planificación hidrológica y planificación urbanística — por cuanto puede determinar la exclusión de actividades urbanizadoras en suelo que merece protección en atención, entre otros, a sus valores ambientales-).

Por otro lado, algunas de las instituciones más características del derecho administrativo cumplen también relevantes funciones en este ámbito de la protección ambiental. De este modo, la institución del dominio público — sobre todo cuando dicha calificación recaiga en bienes pertenecientes al denominado demanio natural (aguas, zona marítimo-terrestre, montes, vías pecuarias) - determina la exclusión del comercio de este tipo de bienes, lo que ya de por sí constituye un principio de protección frente a las actividades contaminantes o de degradación. Del mismo modo, la institución del servicio público, con todas sus limitaciones conceptuales y de régimen jurídico, permite retener la titularidad o, por lo menos, el control público de determinadas actividades de indudable relevancia ambiental (recogida y tratamiento de residuos, abastecimiento, saneamiento y depuración de aguas residuales...).

Otro instrumento en manos de la Administración pública que puede servir a los fines proteccionistas es la institución de la responsabilidad, por cuanto sirve para exigir la indemnización y reparación de los daños ambientales. Esta materia, dadas las peculiaridades 
del daño ambiental, que en muchas ocasiones recae sobre bienes de titularidad colectiva y cuya relación de causalidad con la acción no siempre es fácil establecer (contaminación de fuente difusa, aparición posterior de los daños ambientales, etc.), requería desde hace tiempo una regulación específica en España que, finalmente, por mandato del derecho comunitario, ha determinado la aprobación de la Ley 26/2007, de 23 de octubre, de responsabilidad por daños al medio ambiente.

Además de estas potestades e instituciones generales del derecho administrativo, el ordenamiento jurídico ha desarrollado técnicas específicas para la protección del medio ambiente. Entre ellas destaca la evaluación de impacto ambiental tanto de planes y programas (la denominada evaluación ambiental estratégica, regulada mediante Ley 9/2006, de 28 de abril) como de proyectos públicos o actividades privadas (la denominada evaluación de impacto ambiental de proyectos, regulada hoy en el Real Decreto Legislativo 1/2008, de 11 de enero).

La Administración utiliza otras técnicas específicamente ambientales como son la determinación, preferentemente normativa, de límites de emisión e inmisión para determinadas sustancias contaminantes. En este sentido, los límites de emisión atienden a la cantidad de contaminante que emiten fuentes concretas (por ejemplo, tubos de escape, chimeneas de industrias, puntos de evacuación de aguas usadas, etc.). Los límites de inmisión, por su parte, se refieren a la fijación de valores límite de sustancias contaminantes en determinadas zonas (límites de calidad ambiental).

Por otro lado, la técnica de zonificación determina que, en muchas ocasiones, las normas ambientales obliguen a la Administración pública a que, en virtud de diferentes criterios y por distintas razones —como, significativamente, la especial sensibilidad del área-, se establezcan zonas en las que los límites de contaminantes van a ser más estrictos o, por el contrario, se definan zonas en las que se van a rebajar los criterios de protección. Entre otras, destacan las zonas sensibles a los efectos de la depuración de aguas residuales urbanas, las zonas vulnerables a la contaminación por nitratos derivados de la actividad agrícola, etc.

En otras ocasiones, la técnica consiste en intentar utilizar los propios mecanismos del mercado económico para ponerlos al servicio de la protección ambiental de modo que las empresas que actúan en una determinada zona, si reducen sus niveles de contaminación, puedan "vender" esa cuota de contaminación que han dejado de producir. Para que efectivamente redunden en una mejora del medio ambiente, el uso de estas técnicas 
denominadas "permisos negociables o derechos de contaminación transmisibles" debe partir de estos presupuestos: fijación de unos niveles máximos de contaminación ambiental y actividad administrativa reguladora y de inspección del buen funcionamiento de ese mercado.

En los Estados Unidos, de donde provienen este tipo de fórmulas, se utiliza este sistema fundamentalmente para dos ámbitos: contaminación atmosférica y contaminación de aguas. En relación con la protección frente a los GEI — gases de efecto invernadero-, la creación de un mercado de permisos negociables ha sido el sistema ideado en el Protocolo de Kioto para intentar frenar el proceso de cambio climático.

Por último, destacan los instrumentos de protección ambiental voluntarios que persiguen igualmente la finalidad de que sea el propio mercado económico el que procure la mejora ambiental. También se basan en la conciencia de los consumidores a la hora de elegir productos o de contratar empresas respetuosas con el medio ambiente (etiquetas ecológicas, auditorías ambientales y sistemas de gestión ambiental de las empresas).

Especial relevancia adquieren en estos últimos tiempos las técnicas voluntarias en relación con la protección de espacios naturales, las cuales pretenden involucrar a todos los sectores, públicos y privados, en la protección de la biodiversidad, y entre las cuales se encuentra la custodia del territorio. Si se pretende conservar la biodiversidad, no basta con limitarse al establecimiento de instrumentos de policía administrativa, que se han revelado insuficientes en relación con los espacios naturales protegidos (López Ramón, 2009: 268).

\section{EL RÉGIMEN JURÍDICO DE LA CUSTODIA DEL TERRITORIO DISEÑADO POR LA LEY 42/2007, DE 13 DE DICIEMBRE, DEL PATRIMONIO NATURAL Y DE LA BIODIVERSIDAD}

El tratamiento jurídico de los espacios protegidos ha ido evolucionando desde que se aprobara, a principios del siglo XX, la Ley de Parques Nacionales de 7 de diciembre de 1916. En los comienzos de esta evolución histórica y jurídica no se consideró la custodia del territorio como herramienta complementaria de gestión. Ha sido la reciente Ley 42/2007, de 13 de diciembre, del Patrimonio Natural y de la Biodiversidad la que ha sentado las bases de dicha filosofía de conservación.

Dada la aplicación potencial de la custodia del territorio a los espacios naturales, es adecuado realizar una breve introducción a la diversa normativa española en materia de espacios naturales. Así, tras la primera ley estatal de 1916, el Estado elaboró la Ley de Montes de 8 de 
junio de 1957, que derogaba la anterior y dejaba los espacios naturales muy vinculados a la política forestal. A continuación se elaboró la Ley de 1975, que mantuvo las líneas maestras que se venían aplicando hasta el momento. Mención especial merece la Ley 4/1989, de 27 de marzo, de Conservación de los Espacios Naturales y de la Flora y Fauna Silvestres, que tuvo que hacer frente a la reiterada oposición de las comunidades autónomas en varias cuestiones, gran parte resueltas en diversas sentencias del Tribunal Constitucional. Una de las más recientes es la Sentencia 294/2004, de 10 de noviembre, que otorgó la competencia de gestión de los parques nacionales a las comunidades autónomas, que hasta ese momento correspondía a la Administración del Estado. La doctrina, y más aún la aplicación práctica de este nuevo reparto competencial, serán las que determinen la adecuación de este criterio. Sin embargo, algunos autores ya señalan que, aunque la gestión de los parques nacionales por las comunidades autónomas fuera el principio jurídico que derivara de la Constitución, es lógica y loable la crítica realizada por algunas organizaciones ecologistas, según las cuales, el Estado está menos limitado en la conservación estricta del entorno por encontrarse la Administración estatal más alejada de las presiones locales que pudieran entrar en contradicción con la política proteccionista (Esteve Pardo, 2008: 184).

La Ley 42/2007 no introduce grandes novedades en la regulación de los espacios naturales. Añade a las categorías ya existentes en la legislación anterior las "áreas marinas protegidas" y las “áreas protegidas por instrumentos internacionales". Introduce mayor claridad en relación con las disposiciones sobre la Red Natura 2000. De este modo, y con la salvedad del título competencial de gestión de parques nacionales atribuido a las comunidades autónomas, la regulación básica actual de espacios naturales se mantiene sin grandes cambios con respecto a la Ley $4 / 1989$.

Sin embargo, sí se reconoce en el preámbulo de la nueva ley estatal que los desarrollos normativos en materia de protección de la biodiversidad y el patrimonio natural promovidos por las comunidades autónomas habían permitido un adecuado nivel de conservación, si bien se consideraba necesaria una nueva regulación más ambiciosa y capaz de responder a las exigencias de las generaciones futuras.

En la actualidad, los espacios naturales que pueden definirse en nuestro país se integran bajo tres denominaciones genéricas: espacios naturales protegidos, espacios protegidos Red Natura 2000 y áreas protegidas por instrumentos internacionales. 
Entre los primeros se encuentran los parques: parques nacionales (que gozan de una regulación específica a través de la Ley 5/2007, de 3 de abril), reservas naturales, áreas marinas protegidas, monumentos naturales y paisajes protegidos.

Dentro del segundo grupo se incluyen los lugares de interés comunitario (LIC) antes de su transformación en zonas de especial conservación (ZEC), y las zonas de especial protección para las aves (ZEPA). Este segundo bloque forma la Red Ecológica Europea Natura 2000, derivada de la Directiva Aves y la Directiva Hábitats (Directiva 79/409/CEE y Directiva 92/43/CEE, respectivamente). Se observa cómo, en la protección de espacios naturales, el derecho comunitario ha ido incrementando su importancia, en consonancia con el valor que ha adquirido la política comunitaria como motor del derecho ambiental español (Fortes Martín, 2005: 25).

El régimen establecido por ambas directivas es un tanto impreciso, lo que ha permitido a los Estados miembros elegir con total libertad la forma y los medios para alcanzar sus objetivos, lo que encaja perfectamente con el principio rector de las relaciones entre las instituciones comunitarias y los Estados: la subsidiariedad. Esta es la principal ventaja del uso de las directivas como categoría jurídica en la política ambiental europea, dada la diversidad geográfica y administrativa de los distintos países que constituyen la Unión (Muñoz Amor, 2005: 80).

La Ley 42/2007 incorpora y desarrolla las pretensiones de ambas directivas, garantizando en este ámbito la claridad y seguridad jurídica. Sin embargo, el nuevo tratamiento normativo ignora la participación expresa de las entidades locales en la declaración de los LIC así como en la de las ZEPA. Esto implica que la Ley 42/2007 no asegura el derecho constitucional de los municipios de intervenir en los asuntos que les afecten, ya que la delimitación de espacios protegidos puede influir en competencias netamente locales, como el planeamiento del suelo (Esteve Pardo, 2008: 196).

Finalmente, la nueva ley estatal introduce el concepto de áreas protegidas por instrumentos internacionales en su artículo 49, para designar aquellos espacios naturales formalmente definidos conforme a los convenios y acuerdos internacionales en la materia de los que sea parte España, algunos de los cuales se enumeran en el precepto citado.

La gestión de los espacios naturales protegidos corresponde a las comunidades autónomas, tal como determina el artículo 36 de la Ley 42/2007. Igualmente, es labor de las comunidades autónomas la conservación y gestión de los espacios protegidos Red Natura 2000, en 
respuesta al artículo 45 de la Ley estatal. Hay que destacar al respecto que la Ley 42/2007 incorpora el artículo 6.1 de la Directiva Hábitats, según el cual las medidas de conservación podrán incluir "adecuados planes de gestión, específicos a los lugares o integrados en otros planes de desarrollo, y las apropiadas medidas reglamentarias, administrativas o contractuales que respondan a las exigencias ecológicas de los tipos de hábitats naturales del Anexo I y de las especies del Anexo II presentes en los lugares". Finalmente, el régimen de las áreas protegidas por instrumentos internacionales, de conformidad con el artículo 49 de la Ley 42/2007, será el de los convenios y acuerdos internacionales correspondientes "sin perjuicio de los regímenes de protección, ordenación y gestión específicos cuyo ámbito territorial coincida total o parcialmente con dichas áreas, siempre que se adecuen a lo previsto en dichos instrumentos internacionales".

La aplicación de los preceptos legales anteriormente enumerados, es decir, la protección y conservación de los tres grupos de espacios naturales, se ha hecho principalmente a través de planes de gestión y de medidas reglamentarias. Sin embargo, la Ley presenta otros posibles mecanismos dotados de un amplio potencial - de carácter netamente administrativo o, incluso, contractual- que aún hoy están escasamente explotados. Estas actuaciones permitirían implicar en la conservación de los valores naturales a un mayor número de agentes sociales, lo que reduciría la carga sobre los poderes públicos o complementaría la actuación de estos.

Tradicionalmente, ha sido la Administración la que ha desarrollado unilateralmente actuaciones de protección y conservación de la biodiversidad. Debido a que los recursos humanos, materiales y económicos para tales fines son limitados, el interés de los poderes públicos se suele centrar en recursos naturales de relevancia reconocida o de interés general. Sin embargo, existen valores que no tienen suficiente entidad para exigir una atención específica por parte de la Administración, pero cuya conservación o mejora sí sería conveniente. Por ello, las medidas administrativas, y más aún las contractuales, son capaces de involucrar a los propietarios y usuarios de terrenos, a la sociedad civil organizada, a la empresa privada y a la población en general en la conservación de la naturaleza, centrando sus esfuerzos sobre elementos o espacios naturales que, de otro modo, no serían correctamente atendidos. La disposición de la Ley 42/2007 para promover acuerdos voluntarios con propietarios y usuarios en materia de planificación y gestión de espacios protegidos fue clara ya en el borrador presentado al Parlamento en junio de 2007 (Lasagabaster Herrarte, 2007: 210). 
En definitiva, la consideración de otros mecanismos de protección por parte de la Ley 42/2007 (más allá de la intervención unilateral de la Administración) no es más que el reconocimiento formal de la valía de una sociedad civil activa y comprometida con su entorno.

La custodia del territorio es una de estas posibles estrategias. La Ley del Patrimonio Natural y de la Biodiversidad la define en su artículo 3.9 como "el conjunto de estrategias o técnicas jurídicas a través de las cuales se implican a los propietarios y usuarios del territorio en la conservación y uso de los valores y los recursos naturales, culturales y paisajísticos".

Esta definición, un tanto genérica, pretende dar una visión global del concepto, y dota a la custodia del territorio de un carácter dinámico y flexible que permite integrar un elevado número de técnicas adaptadas a cada espacio y realidad física, social y económica. De esta forma, la custodia se constituye como una novedosa y complementaria herramienta de gestión (y nunca sustitutiva de otros mecanismos administrativos de protección existentes) que promueve la actuación de los propietarios y usuarios de las fincas afectadas, lo que favorece el mantenimiento o incluso la mejora de las funciones y los procesos ecológicos del territorio sin que ello suponga una afectación negativa a los beneficios económicos que proporciona su explotación. Se trata, por lo tanto, de un modelo perfectamente viable en zonas donde el suelo, el agua y los recursos naturales se exploten o comercialicen. Más aún, la custodia del territorio desea presentarse como una opción atractiva para el titular de la finca privada o municipal a la hora de gestionar sus recursos. Algunos de los beneficios que pueden recibir los propietarios o usuarios del territorio involucrados son: asesoramiento sobre las novedades técnicas y legales que afectan a su propiedad, aportación directa de recursos por parte de las entidades de custodia en la gestión del territorio, voluntarios que realicen actividades puntuales, o reconocimiento social por su participación en una iniciativa de conservación.

Por lo tanto, uno de los agentes involucrados en las técnicas de custodia del territorio son los propietarios o usuarios de terrenos que, de manera voluntaria, asumen el compromiso de realizar o colaborar en actuaciones de gestión sostenible. Además de estos se requiere la presencia de las entidades de custodia del territorio, que se definen en el artículo 3.37 de la Ley 42/2007 como “organizaciones públicas o privadas, sin ánimo de lucro, que lleven a cabo iniciativas que incluyan la realización de acuerdos de custodia del territorio para la conservación del patrimonio natural y la biodiversidad". 
Pueden actuar como entidades de custodia del territorio organizaciones tan diversas como asociaciones de vecinos, organizaciones ecologistas, fundaciones, ayuntamientos y cualquier otro tipo de ente público o privado, siempre y cuando incluya entre sus objetivos la participación activa en la conservación del patrimonio natural y la biodiversidad mediante acuerdos de custodia. De este modo, pueden surgir proyectos de custodia de muy diversa envergadura y coste económico, según las características de cada entidad de custodia del territorio.

La participación de dichas organizaciones en la gestión de los espacios naturales mediante la custodia del territorio puede considerarse, por lo demás, un ejemplo de aplicación del Convenio de Aarhus de 1998, del $6^{\circ}$ Programa de Acción Comunitario en materia de Medio Ambiente y de la Ley 27/2006, de 18 de julio, por la que se regulan los derechos de acceso a la información, de participación pública y de acceso a la justicia en materia de medio ambiente. La aparición, en el ámbito de la participación ambiental, de las fundaciones o asociaciones responde claramente a la unión de la sociedad civil en auxilio de los poderes públicos para el logro de fines de interés general, entre los que se encuentra la defensa del medio ambiente (Llodrá Grimalt, 2008: 40).

Las referencias a la custodia del territorio encuentran un ulterior desarrollo en el título $\mathrm{V}$ "Fomento del conocimiento, la conservación y restauración del patrimonio natural y la biodiversidad", según el cual las entidades de custodia, como entidades sin ánimo de lucro, podrán acogerse a ayudas concedidas por el Ministerio de Medio Ambiente cuando desarrollen "actuaciones que afecten a más de una Comunidad Autónoma y que tengan por objeto la conservación del patrimonio natural y la biodiversidad, previa aceptación, en su caso, de las Comunidades Autónomas cuya gestión del patrimonio natural y biodiversidad sea afectada" (art. 71 de la Ley 42/2007). El apoyo económico a las iniciativas de custodia del territorio también podrá derivar del Fondo para el Patrimonio Natural y la Biodiversidad, cuyo objeto es "poner en práctica aquellas medidas destinadas a apoyar la consecución de los objetivos de esta Ley, así como la gestión forestal sostenible, la prevención estratégica de incendios forestales y la protección de espacios forestales y naturales en cuya financiación participe la Administración General del Estado" (art. 74.1), y entre cuyas actuaciones de financiación se incluyen las "específicas relacionadas con la custodia del territorio" (art. 74.2, letra $m)$.

Por lo tanto, con la intervención de las entidades de custodia del territorio, la protección de los recursos naturales puede beneficiarse de un régimen jurídico que permite a estas 
organizaciones obtener fondos públicos que sirvan de apoyo a los acuerdos voluntarios con los propietarios de las fincas privadas.

El posible acceso a estos fondos públicos por parte de las entidades de custodia del territorio es uno de los mecanismos que incrementará el valor de esta iniciativa de gestión. En todo caso, antes de iniciar cualquier acuerdo, estas entidades deberán determinar los costes y las necesidades materiales y económicas de la actividad a desarrollar, con objeto de evaluar si cuentan con los fondos necesarios para realizar las actuaciones y proceder a su seguimiento a escala espacial y temporal. Se entiende, por lo tanto, que este apoyo económico y financiero al que podrán optar las entidades de custodia del territorio supondrá un empuje definitivo a sus iniciativas.

Más aún, en el artículo 71.1 de la Ley 42/2007 se establece que las administraciones públicas promoverán de manera específica la custodia del territorio "mediante acuerdos entre Entidades de custodia y propietarios de fincas privadas o públicas que tengan por objeto principal la conservación del patrimonio natural y de la biodiversidad". Asimismo, en su artículo 72.2 se determina que, en caso de que la Administración general del Estado sea la titular de terrenos en espacios naturales, "podrá llevar a cabo el desarrollo de acuerdos de cesión de su gestión, total o parcial de los mismos, a Entidades de custodia del territorio. Estos acuerdos para la cesión de la gestión, se establecerán por escrito en forma de convenio administrativo plurianual que preverá el sistema de financiación para su desarrollo, bien mediante aportaciones económicas, edificaciones, equipamientos, maquinaria, vehículos o cualquier otro bien o servicio, así como las directrices mínimas de gestión, fijadas en un precedente plan de gestión".

Por lo tanto, el tercer agente necesario para el desarrollo de actuaciones de custodia del territorio es la Administración pública, que debe fomentar y facilitar su desarrollo. Sin embargo, no hay que olvidar que serán las entidades de custodia y los propietarios de los terrenos los que, de manera libre e independiente de la Administración, negociarán y pondrán en práctica los acuerdos de custodia. Esto da a las asociaciones, los ayuntamientos y las organizaciones de diferente entidad un gran potencial para entablar acuerdos con propietarios, los cuales serán conscientes de que, para poder gestionar sus recursos de manera respetuosa con el medio ambiente, no es necesario tratar directamente con la Administración, sino que cuentan con otras vías, si cabe más directas y personalizadas. 
Los mecanismos para formalizar los acuerdos de custodia pueden ser muy diversos, amparándose en diferentes fórmulas jurídicas; sin embargo, todos ellos se fundamentarán en la voluntad privada de las entidades de custodia e, incluso, en la motivación personal de cada individuo por la protección del entorno basada en sus propias creencias, inquietudes y sentido de la responsabilidad social.

No se puede, pues, obviar el papel de la Administración como tercer agente indispensable en la custodia del territorio, puesto que, de acuerdo con el artículo 71.1 de la Ley 42/2007, esta desempeñará un papel estructural, facilitando los cauces y el apoyo legal y económico para que la sociedad pueda llevar a cabo tales acuerdos.

La promulgación de la Ley 42/2007 coincidió en el tiempo con otro importante instrumento normativo con impacto sobre la custodia: la Ley 45/2007, de 13 de diciembre, para el desarrollo sostenible del medio rural. En efecto, la técnica de custodia del territorio puede considerarse un instrumento al servicio del desarrollo sostenible rural, por cuanto cumple uno de los tres objetivos planteados por la Ley: "conservar y recuperar el patrimonio y los recursos naturales y culturales del medio rural a través de actuaciones públicas y privadas que permitan su utilización compatible con un desarrollo sostenible" (art. 2.1, letra $c$, de la Ley 45/2007).

De forma más concreta, la custodia del territorio podrá beneficiarse del apoyo a la agricultura territorial que promueve la Ley 45/2007 en su artículo 16, por cuanto dicha filosofía de gestión es compatible con un desarrollo sostenible del medio rural. Asimismo, las actuaciones de custodia del territorio que se desarrollen en espacios naturales Red Natura 2000 podrán incluirse en el sistema nacional de Incentivos Económicos Regionales, ya que estos dan preferencia a toda actividad económica que se realice en zonas rurales prioritarias, entre las que se incluyen los LIC y las ZEPA (art. 17.1 de la Ley 45/2007).

\section{CONCLUSIONES}

Primera. La degradación ambiental constituye hoy una de las preocupaciones fundamentales de la sociedad ${ }_{2}$ y los poderes públicos, en consecuencia, han generalizado y profundizado los instrumentos de intervención administrativa para la protección de nuestros recursos naturales y sus ecosistemas asociados. La evolución del ordenamiento jurídico en este sector, desde la ya lejana aprobación del Reglamento de Actividades Molestas, Insalubres, Nocivas y Peligrosas en 1961, determina la progresiva utilización de instrumentos de intervención 
directa sobre actividades privadas basados en las tradicionales técnicas de intervención administrativa. Sin embargo, en la actualidad adquieren cada vez más presencia otras técnicas alternativas de gestión ambiental basadas en la voluntariedad y en la participación directa, individualmente o en grupos, de los propios ciudadanos.

Segunda. En efecto, una vez aceptada y valorada la intervención administrativa en beneficio de la protección del patrimonio natural, el siguiente paso lo constituye el reto de garantizar la participación de todos los ciudadanos en las decisiones administrativas y de gestión del medio ambiente, siendo este uno de los tres pilares básicos del Convenio de la Comisión Económica para Europa de Naciones Unidas sobre el acceso a la información, la participación del público en la toma de decisiones y el acceso a la justicia en materia de medio ambiente, firmado el 25 de junio de 1998. El conocido como Convenio de Aarhus parte del postulado de que, para que los ciudadanos puedan disfrutar del derecho a un medio ambiente saludable y cumplir el deber de respetarlo y protegerlo, deben tener acceso a la información medioambiental relevante, deben estar legitimados para participar en los procesos de toma de decisiones de carácter ambiental y deben tener acceso a la justicia cuando tales derechos les sean negados.

Tercera. La custodia del territorio puede integrarse en dicho objetivo general de participación pública, por cuanto se considera una herramienta que permite a los ciudadanos participar, a través de entidades organizadas, como complemento a las actuaciones públicas en determinadas áreas de valores especiales naturales, culturales o paisajísticos. A la vez, la custodia del territorio debe considerarse un paso hacia delante de la sociedad, en la medida en que tiende a sacar del aletargamiento a las sociedades más avanzadas, al permitir que estas pasen a ser cada vez más activas en la protección de su entorno, así como en su exigencia de políticas y actuaciones públicas acordes con sus nuevas pretensiones.

Cuarta. Por otro lado, la propiedad privada juega un papel relevante en la política de espacios protegidos, puesto que en muchas ocasiones sesga y divide el patrimonio natural, lo que dificulta las tareas de protección de la Administración. La Red Natura 2000 constituye un claro ejemplo del interés por garantizar la continuidad en sus iniciativas y por evitar o reducir en lo posible la desprotección y el colapso de poblaciones de organismos aisladas, tal como se muestra en su propia definición como "red ecológica europea coherente" (artículo 3.1 de la Directiva 92/43/CEE del Consejo, de 21 de mayo, relativa a la conservación de los hábitats naturales y de la fauna y flora silvestres). La custodia del territorio incorporada a tales objetivos permite involucrar a los propietarios que se encuentran dentro, o entre espacios 
protegidos, en la protección y explotación sostenible de los recursos naturales, con lo que se obtienen beneficios para todos.

Quinta. En España, la Ley 42/2007 sentó las bases para la utilización de la custodia del territorio como herramienta complementaria de gestión del entorno natural, sin determinar un régimen específico y claro al respecto. Sin embargo, al incluir la custodia del territorio en los mecanismos genéricos que prevé de fomento de protección de la biodiversidad y del patrimonio natural, la Ley está reconociendo la validez, e incluso la necesidad, de los acuerdos de custodia para una mejor gestión del entorno y de sus recursos naturales.

Sexta. La Ley 45/2007 deja abierta la posibilidad de integrar la custodia del territorio en el desarrollo rural sostenible. Sin embargo, y a pesar del tiempo transcurrido, aún hay que esperar a comprobar si a esta seguridad jurídica inicial responderá de manera coherente la Administración, y más aún la de ámbito local, que por ser la más próxima al territorio percibe de manera más directa las necesidades de cada zona.

Séptima. El único escenario posible de la custodia del territorio deben ser los terrenos que no gozan de una figura legal de protección específica o de la atención preferente por parte de la Administración en su actividad proteccionista y de gestión de los recursos naturales. De modo que en ningún caso y bajo ninguna circunstancia podrá utilizarse por parte de los poderes públicos como forma de abandonar su obligación constitucional de "proteger y mejorar la calidad de la vida y defender y restaurar el medio ambiente". En todo caso, son instrumentos complementarios que deberán aprender a convivir en un entorno próximo.

Octava. La participación expresa de los municipios en la declaración y gestión de las áreas sujetas a una protección especial es un elemento más de su actividad de ordenación y planeamiento del suelo, por lo que es necesario dotar a los entes locales de instrumentos concretos que les permitan intervenir, respetando el reparto constitucional de competencias, en los espacios naturales. No pueden obviarse las posibilidades que se abren a los municipios en este ámbito, ya que los ayuntamientos pueden constituirse en entidades de custodia del territorio, lo que favorecería la intervención y participación de la Administración local en la conservación y protección de su propio entorno natural.

Novena. Los fundamentos de la custodia del territorio son sencillos, cercanos y concretos, lo que permite su seguimiento a corto y medio plazo, así como su comprensión por los agentes potenciales. Por otro lado, el amparo legal que se le ha otorgado recientemente revaloriza el esfuerzo de los propietarios por la protección del medio ambiente, lo que permite el 
reconocimiento, por parte de la sociedad, de la utilidad y solidaridad derivada de una propiedad privada involucrada en el interés general.

Sin embargo, la consolidación de la custodia del territorio requiere no solo el apoyo jurídico, sino también un extenso reconocimiento y difusión social que anime a los propietarios a su integración en proyectos de custodia, así como a posibles candidatas a entidades de custodia a configurarse como tales. Y esto solo se conseguirá cuando las entidades de custodia puedan desarrollar sus iniciativas y acuerdos en un marco de derecho riguroso, y cuando lleven a cabo una difusión pública de sus actuaciones con el pleno apoyo de la Administración. En este sentido, es loable la tarea que ha iniciado la Fundación Biodiversidad a través de la Plataforma Estatal de Custodia del Territorio, así como de otras entidades de reciente creación, de las que se espera que den el empuje definitivo a esta técnica de conservación complementaria a las tradicionales. Únicamente la continuidad en esta línea de trabajo permitirá, en todo caso, construir un mensaje conjunto de las entidades involucradas que permita hacer llegar a los propietarios y al público en general, de manera clara y homogénea, las oportunidades que brinda la custodia del territorio a nuestra riqueza natural.

Décima. En el ámbito específico de la Comunidad Autónoma de la Región de Murcia se impone la, por otra parte, inaplazable elaboración de una nueva Ley de Espacios Naturales que sustituya la prácticamente fenecida Ley 4/1992, de 30 de julio, de Ordenación y Protección del Territorio y que acoja, como complemento a los instrumentos de protección, esta figura de la custodia del territorio, de modo que las iniciativas ciudadanas y locales que se planteen en este sector encuentren un marco completo regulador. No obstante, no puede dejar de señalarse que la prioridad es reconstruir una auténtica estrategia regional en relación con los espacios naturales protegidos donde la custodia pueda jugar un papel complementario, pero que no sirva de disculpa para hacer dejación de las potestades administrativas de intervención, que son las que verdaderamente crean el entramado donde estas iniciativas, basadas en la voluntariedad, encuentran su recto sentido y adecuado lugar. 


\section{BIBLIOGRAFÍA}

- Alonso García, E./Lozano Cutanda, B., Diccionario de Derecho Ambiental, Iustel, Madrid, 2006 (Voces: "Reservas Naturales Privadas. La Custodia del Territorio" y "Red Natura 2000").

- Artimaño Del Río, P./MuÑOZ FernÁNDEZ, S., La conservación de los espacios naturales: estrategias urbanísticas de protección, La Ley, Madrid, 2002.

- BARreira LóPez, A. (dir.), Estudio jurídico sobre la custodia del territorio, Fundación Biodiversidad, Madrid, 2010.

- BAsora Roca, X./SABATÉ I RotÉs, X., Custodia del territorio en la práctica. Manual de introducción a una nueva estrategia participativa de conservación de la naturaleza y el paisaje (http://www.custodiaterritori.org/docs/xct_castella_web.pdf —último acceso: 23/06/09).

- CANAls Ventín, M. P., "De las comunidades indígenas y locales a la custodia de espacios naturales", Revista Ambienta, núm. 67, 2007, pp. 32-39.

- Conclusiones del Foro-Reunión sobre Custodia del Territorio, Madrid, 16 de noviembre de 2006.

- Conclusiones de las I Jornadas Nacionales sobre la Custodia del Territorio, Declaración de CEMACAM-Torre Guil, Murcia, 2004.

- Conclusiones de las II Jornadas Nacionales sobre la Custodia del Territorio, Declaración de CEMACAM-Torre Guil, Murcia, 2006.

- Conclusiones de las IV Jornadas Estatales sobre Custodia del Territorio, Benia de Onís, Asturias, 2010.

- De Rojas Martínez-Parets, F., "Fórmulas alternativas de protección y gestión de los espacios naturales", monografia asociada a la Revista Aranzadi de Derecho Ambiental, Thompson-Aranzadi, 2006.

- Esteve Pardo, J., Derecho del medio ambiente, Marcial Pons, Madrid, 2008.

- Fortes Martín, A., Vertidos y calidad ambiental de las aguas: regulación jurídicoadministrativa, Atelier, Barcelona, 2005.

- Hervás MÁs, J., Ordenación del territorio, urbanismo y protección del paisaje, Bosch, Barcelona, 2009. 
- JoRDANO FragA, J., "Expropiaciones legislativas en el Derecho ambiental americano", Revista Española de Derecho Administrativo, núm. 85, 1995.

- Josep Picó, M./Sargantal, J./Rosembuj Erujimovich, T. R., "El valor del paisaje y el territorio", Medi Ambient: Tecnología i Cultura, núm. 42, 2008.

- Lasagabaster Herrarte, I. (dir.), Derecho Ambiental. Parte General, LeTE, Bilbao, 2007.

— Derecho Ambiental. Parte Especial I (Espacios naturales, Flora y Fauna, Montes,

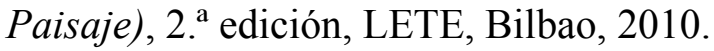

- LlodrÀ Grimalt, F., Lecciones de Derecho ambiental civil, Universitat Illes Balears, Palma de Mallorca, 2008.

- LÓPEZ RAMÓN, F., Política ecológica y pluralismo territorial, Marcial Pons, Madrid/Barcelona/Buenos Aires, 2009.

- MuÑoz Amor, M. M., La calidad de las aguas: régimen vigente y grado de cumplimiento de la normativa comunitaria, Madrid, Ecoiuris, 2005.

- Orón Moratal, G., Custodia del territorio: análisis de incentivos fiscales y propuestas para que sea una realidad en Andalucía, Fundación Andanatura, 2008.

- PAllarés Serrano, A., "El recurso a la custodia del territorio y a los acuerdos voluntarios en el ámbito del patrimonio natural y la biodiversidad", Revista Catalana de Dret Públic, núm. 41, 2010.

- Pietx i Colom, J., "La custodia del territorio en Cataluña", Medi Ambient: Tecnologia $i$ Cultura, núm. 42, 2008.

- SEguí, G., "La custodia del territorio: Menorca: buenas prácticas agrarias y conservación en islas europeas", Actualidad Leader: Revista de desarrollo rural, núm. 42, 2008 (http://www.mapa.es/Desarrollo/pags/RedRural/publicaciones/revista42/AL42_Reservas\%20 Biosfera.pdf —último acceso: 11/04/2011). 